\title{
An approach to familial lymphoedema
}

\author{
Authors: Gabriela E Jones ${ }^{A}$ and Sahar Mansour ${ }^{B}$
}

Lymphoedema is the build-up of lymphatic fluid leading to swelling in the tissues. Most commonly it affects the peripheries. Diagnosis is based on clinical assessment and imaging with lymphoscintigraphy. Treatment is supportive with compression garments, massage, good skin hygiene and prompt use of antibiotics to avoid the complication of cellulitis. Most commonly, lymphoedema occurs as a result of damage to the lymphatic system following surgery, trauma, radiation or infection. However, it can be primary, often associated with a genetic defect that causes disruption to the development of the lymphatic system. Common genetic conditions associated with lymphoedema include Turner syndrome and Noonan syndrome; however, there are numerous others that can be classified based on their clinical presentation and associated features. Herein we discuss how to diagnose and classify the known primary lymphoedema conditions and how best to investigate and manage this group of patients.

\section{Introduction}

The lymphatic system is a network of connected vessels, nodes and tissues, whose main function is in the body's defence against infection. It also returns excess fluid from the tissues and fatty acids from the bowel to the bloodstream. ${ }^{1}$ Disruption of the normal flow of the lymphatic system leads to swelling (oedema). Most commonly, lymphoedema occurs as a result of damage to the lymphatic system following surgery, trauma, radiation or infection. However, it can be primary, associated with a disruption to the development or the function of the lymphatic system causing impaired drainage of lymph. This group of conditions will be the focus of the current review.

\section{Clinical presentation}

The presentation is most commonly associated with swelling in the extremities; however, it may involve any body site (eg facial or genital oedema). In addition, there may be systemic

Authors: ${ }^{A}$ consultant in clinical genetics, Department of Clinical Genetics, University Hospitals Leicester NHS Trust, Leicester, UK; ${ }^{B}$ consultant and honorary professor in clinical genetics, Department of Clinical Genetics, St Georges Hospital and St George's, University of London, London, UK (or visceral) involvement with chylothoraces, pericardial effusions, chylous reflux or intestinal lymphangiectasia (Fig 1). In primary lymphoedema, the underlying abnormality is usually present at birth but the swelling, although often congenital, may not develop until puberty or adulthood. Lower limb lymphoedema can be confirmed by a positive Stemmer's sign, which is a thickened cutaneous fold of the second toe or second finger that can be gently pinched and lifted. ${ }^{2}$ There may also be skin changes, such as papillomatosis (Fig 1b), lymphangiectasia or lymphorrhoea in chronic lymphoedema and deep interphalangeal creases and nail changes with small, dysplastic, 'ski-jump' nails (Fig la and 1b).

\section{Genetic basis of primary lymphoedema}

For many years it was known that there were some families where there was likely inherited lymphoedema with or without additional features. However, it was not until 2000 that the gene for Milroy syndrome, FLT4 (VEGFR3), was discovered., Following this, numerous other genes that are associated with lymphatic disease have been discovered. Connell et al detailed a classification system and diagnostic algorithm based on onset

\section{Key points}

Primary lymphoedema is caused by abnormal development or function of the lymphatic system

Primary lymphoedema can be classified according to age of onset, pattern of lymphoedema and associated features

There are many chromosomal or genetic conditions in which lymphoedema is a reported feature

Management of lymphoedema is mainly supportive with massage, compression garments and personal care; however, with better understanding of the genetic basis, targeted therapies may be an option for some conditions

Genetic testing may help to clarify the diagnosis and allow accurate risk assessment for relatives

KEYWORDS: Chromosomal, hereditary, lymphatic, primary lymphoedema, single gene 

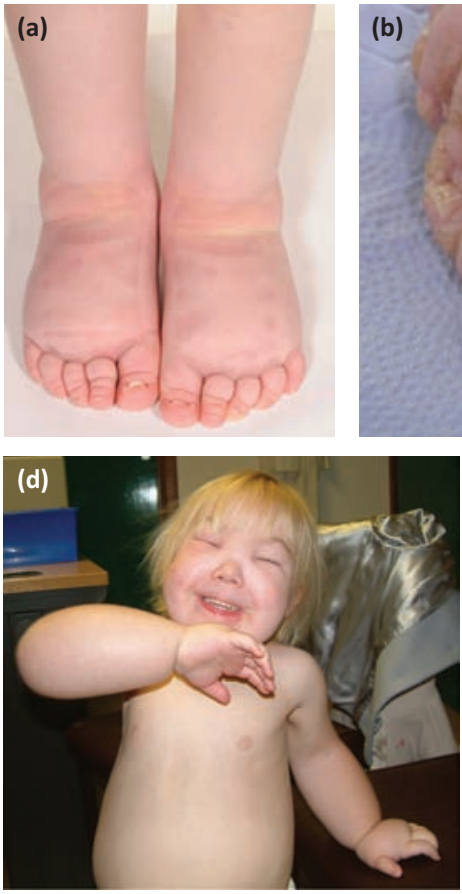
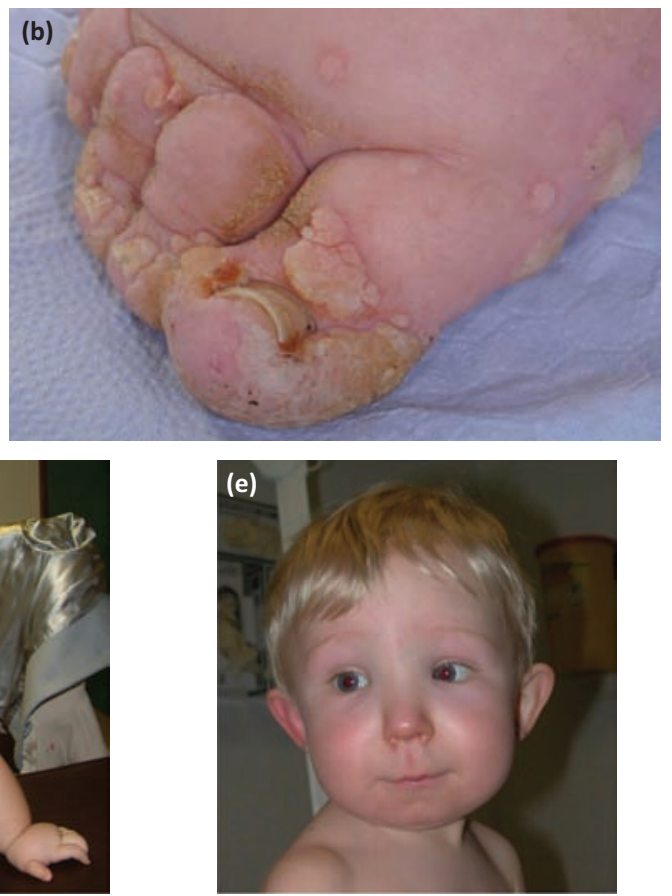

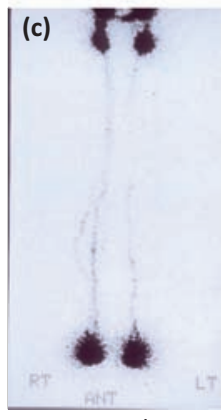

Normal

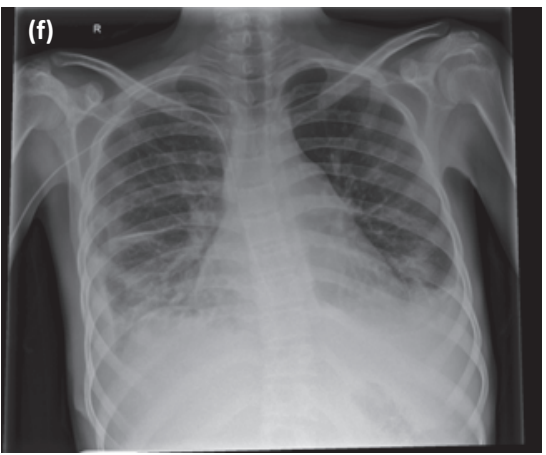

Fig 1. Images demonstrating different types of primary lymphoedema, lymphoscintigraphy and possible complications. (a) Bilateral pedal oedema, deep interphalangeal creases and small, dysplastic, 'ski-jump' toenails in an individual with Milroy disease; (b) longstanding pedal oedema with papillomatosis in a female with Turner syndrome; (c) lymphoscintigraphy after 2 hours in a normal control, an individual with lymphoedema-distichiasis syndrome demonstrating lymphatic reflux, and an individual with Milroy disease showing paucity of lymphatic vessels; (d) generalised lymphoedema affecting the face, hands and feet in a patient with Hennekam syndrome (CCBE1); (e) facial oedema in a patient with PIEZO1 related-lymphoedema; (f) a chest radiograph demonstrating bilateral chylothoraces in a patient with Noonan syndrome.

and site of lymphoedema and associated features. ${ }^{5}$ There are five main subgroups:

1 syndromic

2 lymphoedema with systemic/visceral involvement

3 overgrowth/vascular malformation syndromes

4 congenital onset $(<1$ year $)$

5 later onset ( $>1$ year).

Since then, two new genes - PIEZO1 and EPHB4 - have been identified as a cause of generalised lymphatic dysplasia ${ }^{6,7}$ and the overgrowth/vascular malformation syndromes are now collectively known as the PIK3CA-related overgrowth spectrum (PROS) disorders because they are caused by somatic mutations in the phosphatidylinositol-3-kinase (PI3K)/AKT/mTOR pathway. ${ }^{8}$ An adapted classification system is presented in Fig 2. A summary of the features and presentations of some of the conditions can be found in Table 1 .

\section{Syndromes associated with lymphoedema}

\section{Turner syndrome}

Turner syndrome is a genetic condition affecting females who have only one normal X chromosome. Common features include antenatal hydrops or cystic hygroma, short stature, mild learning difficulties, congenital heart disease (commonly coarctation of the aorta), congenital renal anomalies, lymphoedema and infertility. Examination may identify low posterior hairline with webbed neck, widely spaced nipples and increased carrying angle. Lymphoedema typically presents at birth with four-limb lymphoedema, which often resolves, but may recur later in life. Lymphoscintigraphy suggests that the lymphatic phenotype of Turner syndrome may be due to a failure of initial lymphatic (capillary) function. ${ }^{9}$

\section{Noonan syndrome}

Noonan syndrome is a relatively common condition that follows an autosomal dominant pattern of inheritance. It is associated with alterations in genes encoding the Ras/ MAPK pathway. Common features include antenatal hydrops or cystic hygroma, short stature, mild learning difficulties, congenital heart disease (commonly pulmonary stenosis or hypertrophic cardiomyopathy), cryptorchidism, hernias and bleeding diathesis. Examination may identify distinct facial features (down slanting palpebral fissures, ptosis, low set posteriorly rotated ears) and webbed neck. Congenital lymphoedema is fairly common in this disorder, but a few patients may develop lymphoedema in childhood, with a characteristic pattern of bilateral lower limb lymphoedema, genital swelling with chylous reflux and frequent systemic involvement, including intestinal lymphangiectasia and chylothoraces (Fig 1e), which may be progressive. Lymphoscintigraphy demonstrates reflux and/or rerouting of lymphatic drainage associated with incompetent veins on the venous duplex scans. ${ }^{10}$ 


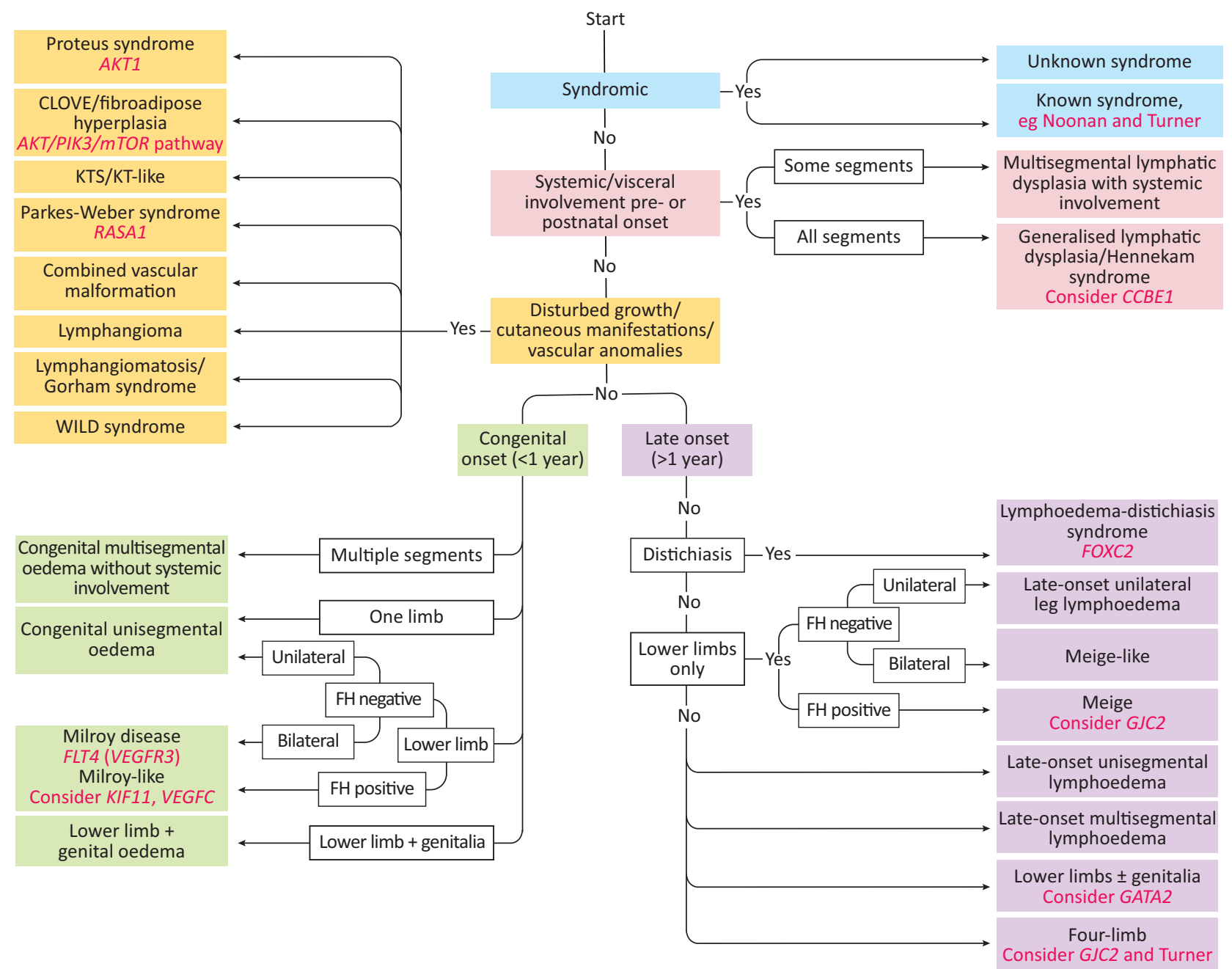

Fig 2. Classification criteria for diagnosis of primary lymphoedema. Genes are marked in italics. Adapted from Connell et al. $.^{5} \mathrm{CLOVE}=\mathrm{congenital}$ lipomatous overgrowth, vascular malformations, and epidermal nevi; $\mathrm{FH}=$ fibroadipose hyperplasia; $\mathrm{KT}$ = klippel-trenaunay; $\mathrm{KTS}=$ klippel-trenaunay syndrome; WILD = warts, immunodeficiency, lymphoedema, dysplasia

\section{Generalised lymphatic dysplasia}

Hennekam syndrome

Hennekam syndrome is a rare condition with an autosomal recessive pattern of inheritance associated with alterations in the CCBE1 and FAT4 genes, ${ }^{11,12}$ which account for approximately $50 \%$ of cases. Presentation is usually with congenital or antenatal onset (hydrops) of generalised severe lymphoedema, lymphangiectasia, learning difficulties, seizures, microcephaly, short stature and characteristic facial features (puffy eyelids, flattened facial profile, hypertelorism, gingival hypertrophy and microstomia) (Fig 1d).

\section{PIEZO1-related lymphatic-related hydrops/generalised} lymphatic dysplasia

This is a newly described condition following autosomal recessive inheritance related to alterations in the PIEZO1 gene. ${ }^{6}$ It is characterised by a uniform, widespread lymphoedema affecting all segments of the body, with systemic involvement - such as pulmonary lymphangiectasia, pleural effusions, chylothoraces and/or pericardial effusions
(Fig 1e). Presentation may be with non-immune hydrops. In comparison to Hennekam syndrome, intelligence is normal, with no seizures or distinct facial features other than swelling.

\section{EPHB4-related lymphatic-related hydrops}

In 2016, Martin-Almedina et al reported two unrelated autosomal dominant families with in utero hydrops/neonatal deaths found to be due to heterozygous missense mutations in EPHB4 on exome sequencing. ${ }^{7}$ There was a high incidence of atrial septal defects in these families. EPHB4 was found to be an important regulator of early lymphatic vascular development and mutations in the gene can cause an autosomal dominant form of non-immune hydrops with variable expressivity, but associated with high mortality rate.

\section{Lymphoedema associated with overgrowth and/or vascular malformations}

PIK3CA-related overgrowth spectrum

In 2015, Keppler-Noreuil et al delineated PROS, a

heterogeneous group of disorders associated with somatic 
Table 1. Primary lymphoedema conditions, including genetic basis and inheritance, onset and nature of lymphoedema and associated features

\begin{tabular}{|c|c|c|c|c|}
\hline Condition & Genetic basis & Inheritance & $\begin{array}{l}\text { Onset and nature of } \\
\text { lymphedema }\end{array}$ & Associated features \\
\hline Turner syndrome & $45, \mathrm{X}$ (or similar) & Sporadic & $\begin{array}{l}\text { Congenital (may be } \\
\text { prenatal), hands and feet }\end{array}$ & $\begin{array}{l}\text { Short stature, webbed neck, widely } \\
\text { spaced nipples and increased carrying } \\
\text { angle, CHD (coarctation of aorta), } \\
\text { renal anomalies, primary infertility, } \\
\text { mild intellectual disability }\end{array}$ \\
\hline Noonan syndrome & $\begin{array}{l}>23 \text { rasopathy } \\
\text { genes including: } \\
\text { PTPN11, SOS1, } \\
\text { RAF1, RIT1, KRAS, } \\
\text { NRAS, BRAF, } \\
\text { MAP } 2 K 1\end{array}$ & $A D$ & $\begin{array}{l}\text { Congenital (may be } \\
\text { prenatal), lower limb Later } \\
\text { onset genital oedema, } \\
\text { chylous reflux, intestinal } \\
\text { lymphangiectasia, and/or } \\
\text { chylothoraces }\end{array}$ & $\begin{array}{l}\text { Short stature, webbed neck, CHD } \\
\text { (pulmonary stenosis or hypertrophic } \\
\text { cardiomyopathy), dysmorphic features, } \\
\text { bleeding tendency, intellectual } \\
\text { disability, cryptorchid testes, pectus } \\
\text { deformities }\end{array}$ \\
\hline Hennekam syndrome & CCBE1 & AR & $\begin{array}{l}\text { Congenital, multi- } \\
\text { segment, facial, } \\
\text { lymphangiectasia }\end{array}$ & $\begin{array}{l}\text { Microcephaly, distinct facial features, } \\
\text { intellectual disability, short stature, } \\
\text { respiratory problems, skeletal anomalies, } \\
\text { anaemia, polysplenia, renal anomalies. } \\
\text { Systemic lymphatic involvement }\end{array}$ \\
\hline $\begin{array}{l}\text { PIEZO1-related lymphatic- } \\
\text { related hydrops/generalised } \\
\text { lymphatic dysplasia }\end{array}$ & PIEZO1 & AR & $\begin{array}{l}\text { Non-immune hydrops, } \\
\text { childhood onset } \\
\text { multisegment }\end{array}$ & $\begin{array}{l}\text { Systemic involvement (chylothoraces } \\
\text { and/or pericardial effusions) }\end{array}$ \\
\hline $\begin{array}{l}\text { EPHB4-related lymphatic- } \\
\text { related hydrops }\end{array}$ & EPHB4 & $A D$ & Non-immune hydrops & Atrial septal defects \\
\hline $\begin{array}{l}\text { PIK3CA-related overgrowth } \\
\text { spectrum (PROS) }\end{array}$ & $\begin{array}{l}\mathrm{PI} 3 \mathrm{~K} / \mathrm{AKT} / \mathrm{mTOR} \\
\text { pathway }\end{array}$ & Somatic & Congenital & $\begin{array}{l}\text { Hypertrophy/overgrowth of bone and } \\
\text { soft tissues resulting in asymmetry, } \\
\text { vascular malformations, naevi/ } \\
\text { pigmentation }\end{array}$ \\
\hline Milroy syndrome & VEGFR3, VEGFC & $A D$ & $\begin{array}{l}\text { Congenital, pedal, lower } \\
\text { limb }\end{array}$ & $\begin{array}{l}\text { Hydrocele, prominent veins, upslanting } \\
\text { toenails, papillomatosis, and urethral } \\
\text { abnormalities in males }\end{array}$ \\
\hline $\begin{array}{l}\text { Microcephaly-chorioretinopathy- } \\
\text { lymphedema-mental retardation } \\
\text { (MCLMR) }\end{array}$ & KIF11 & $A D$ & Congenital, lower limb & $\begin{array}{l}\text { Microcephaly, chorioretinopathy, } \\
\text { intellectual disability, epilepsy, CHD }\end{array}$ \\
\hline Lymphedema distichiasis & FOXC2 & $A D$ & Pubertal, lower limb & $\begin{array}{l}\text { Distichiasis, varicose veins, ptosis, cleft } \\
\text { palate, CHD, renal anomalies }\end{array}$ \\
\hline Emberger syndrome & GATA2 & $A D$ & $\begin{array}{l}\text { Childhood, lower limb } \\
\text { and/or genital }\end{array}$ & $\begin{array}{l}\text { Myelodysplasia, sensorineural hearing } \\
\text { loss }\end{array}$ \\
\hline Primary lymphedema & $\mathrm{GJC2}$ & $A D$ & $\begin{array}{l}\text { Childhood/adolescence or } \\
\text { postnatal, four limb }\end{array}$ & \\
\hline
\end{tabular}

activating mutations in the PI3K/AKT/mTOR pathway. ${ }^{8}$ This group encompasses many conditions that were previously thought to be distinct (proteus, congenital lipomatous overgrowth, vascular malformations, epidermal nevi, scoliosis/skeletal and spinal (CLOVES) syndrome, macrodactyly and the related megalencephaly syndromes, including megalencephaly-capillary malformation [MCAP or $\mathrm{M}-\mathrm{CM}]$ ). However, it is now known that there is significant overlap in the clinical features, which include overgrowth (adipose, muscle, nerve, skeletal), vascular malformations (capillary, venous, arteriovenous malformation, lymphatic) and epidermal naevi.

\section{Congenital lymphoedema}

Milroy disease

Milroy disease is a condition that follows an autosomal dominant pattern of inheritance, characterised by antenatal or congenital onset of bilateral lower limb lymphoedema. Large calibre veins and upslanting 'ski-jump' toenails are commonly seen (Fig 1a). Lymphoscintigraphy identifies functional aplasia, either due to paucity of the lymphatic vessels or abnormal function of the vessels in the lower limbs (Fig 1c). ${ }^{13}$ Alterations in the FLT4 (VEGFR3) gene are causative. ${ }^{3,4}$ In 2013, Gordon et al ascertained that mutations in VEGFC, 
which is a ligand for VEGFR3, are responsible for Milroy-like lymphoedema. ${ }^{14}$

\section{Microcephaly-chorioretinopathy-lymphoedema-mental retardation}

Microcephaly-chorioretinopathy-lymphoedema-mental retardation is associated with alterations in the KIF11 gene ${ }^{15}$ and follows an autosomal dominant pattern of inheritance. It is included in this section as there is a very high incidence of congenital lower limb lymphoedema (46\%). It is characterised by primary microcephaly, chorioretinal dysplasia, typically congenital bilateral pedal lymphoedema and mild to moderate learning difficulties. Epilepsy and congenital heart disease may also be associated. There is significant variability in presentation and reduced penetrance has been reported. ${ }^{16}$

\section{Late onset lymphoedema}

\section{Lymphoedema-distichiasis syndrome}

This condition follows an autosomal dominant pattern of inheritance and is characterised by lower-limb lymphoedema, usually of pubertal onset, and distichiasis (aberrant extra eyelashes originating from the meibomian glands). This may be a whole additional row of eyelashes or a single hair. Distichiasis may lead to corneal irritation, recurrent conjunctivitis and photophobia. Other commonly associated features include ptosis, congenital heart disease and cleft palate. ${ }^{17} \mathrm{FOXC} 2$ is the only gene, to date, in which mutations are known to cause lymphoedema-distichiasis syndrome. ${ }^{18}$ The lymphatic and venous valves in this condition are dysplastic and leaky so there is a high incidence of varicose veins and lymphoscintigraphy shows dermal backflow, suggestive of lymph reflux into the lower limbs (Fig 1c).

\section{Emberger syndrome}

Emberger syndrome is characterised by the combination of lymphoedema and predisposition to development of myelodysplasia and acute myeloid leukaemia with autosomal dominant inheritance. It is caused by alterations in the GATA2 gene. ${ }^{19}$ Presentation is typically with childhood onset (although may be prenatal or congenital), bilateral, pedal $+/-$ genital oedema, which usually predates the haematological abnormalities. There may be immune dysfunction and myelodysplasia (karyotypic anomalies include monosomy 7), which may progress to acute myeloid leukaemia.

\section{GJC2-related lymphoedema}

In 2010, alterations in the GJC2 gene were identified as a cause of autosomal dominant lymphoedema. ${ }^{20}$ Ostergaard et al further characterised the features of this condition, which presents in the first or second decade with four-limb lymphoedema and increased incidence of varicose veins. ${ }^{21}$

\section{Meige syndrome}

This condition presents with lower limb lymphoedema in adolescence or adulthood. There are a number of families suggestive of autosomal dominant inheritance. There are usually no associated features. It is probably the most common form of primary lymphoedema. Lymphoscintigraphy demonstrates poor uptake at 2 hours and rerouting through the deep lymphatics, with the presence of popliteal lymph nodes (which are not usually visualised). No specific genes have been found for this condition.

There are numerous other conditions in which lymphoedema is a reported feature. These may have a chromosomal or single gene cause; however, in some the cause is unknown. A detailed list of these conditions can be found in Connell et al. ${ }^{5}$

\section{Investigations and management}

Following a detailed family history and examination, investigation of lymphoedema includes lymphoscintigraphy examination. This is the imaging of the lymphatic system by injecting a radioactive isotope into the web spaces between the toes (or fingers) and quantification of uptake into the inguinal (or axillary) lymph nodes after 2 hours (Fig 1c). Decreased uptake suggests abnormal lymphatic drainage. If a specific genetic diagnosis is suspected, genetic testing can be arranged. This includes chromosomal analysis, or karyotype (for Turner syndrome), single gene or gene panel testing (if available). These tests can be performed on a peripheral blood sample; however, if PROS is suspected, a skin biopsy should be taken from an affected area and sent for genetic testing. ${ }^{22}$ In view of the somatic nature of this condition, testing of blood may not yield the diagnosis.

In the main, treatment of lymphoedema is supportive. It includes manual lymphatic drainage and compression hosiery/ garments along with skin hygiene advice and appropriate footwear to reduce the risk of complications. Surgical treatment is largely unsuccessful and is not generally recommended. There are currently no effective drug therapies available for the management of primary lymphoedema. However, the use of drugs targeting the PI3K/AKT/mTOR signalling pathway, such as mTOR inhibitors, provides an exciting prospect for patients with PROS. ${ }^{23}$

\section{Conflicts of interest}

The authors have no conflicts of interest to declare.

\section{Acknowledgements}

The authors would like to thank the families for consenting to the publication of clinical details, photographs and images.

\section{References}

1 Alitalo K. The lymphatic vasculature in disease. Nat Med 2011;17:1371-80.

2 Stemmer R. A clinical sign for the early and differential diagnosis of lymphoedema. Vasa 1976;5:261-2.

3 Karkkainen MJ, Ferrell RE, Lawrence EC et al. Missense mutations interfere with VEGFR-3 signalling in primary lymphoedema. Nat Genet 2000;25:153-9.

4 Irrthum A, Karkkainen MJ, Devriendt K, Alitalo K, Vikkula M. Congenital hereditary lymphoedema caused by a mutation that inactivates VEGFR3 tyrosine kinase. Am J Hum Genet 2000;67:295-301.

5 Connell FC, Gordon K, Brice G et al. The classification and diagnostic algorithm for primary lymphatic dysplasia: an update from 2010 to include molecular findings. Clin Genet 2013;84:303-14.

6 Fotiou E, Martin-Almedina S, Simpson MA et al. Novel mutations in PIEZO1 cause an autosomal recessive generalized lymphatic dysplasia with non-immune hydrops fetalis. Nat Commun 2015;6:8085. 
7 Martin-Almedina S, Martinez-Corral I, Holdhus R et al. EPHB4 kinase-inactivating mutations cause autosomal dominant lymphaticrelated hydrops fetalis. J Clin Invest 2016;126:3080-8.

8 Keppler-Noreuil KM, Sapp JC, Lindhurst MJ et al. Clinical delineation and natural history of the PIK3CA-related overgrowth spectrum. Am J Med Genet A 2014;164A:1713-33.

9 Atton G, Gordon K, Brice G et al. The lymphatic phenotype in Turner syndrome: an evaluation of nineteen patients and literature review. Eur J Hum Genet 2015;23:1634-9.

10 Joyce S, Gordon K, Brice G et al. The lymphatic phenotype in Noonan and Cardiofaciocutaneous syndrome. Eur J Hum Genet 2016;24:690-6.

11 Alders M, Hogan BM, Gjini E et al. Mutations in CCBE1 cause generalized lymph vessel dysplasia in humans. Nat Genet 2009;41:1272-4.

12 Alders M, Al-Gazali L, Cordeiro I et al. Hennekam syndrome can be caused by FAT4 mutations and be allelic to Van Maldergem syndrome. Hum Genet 2014;133:1161-7.

13 Brice GW, Mansour S, Ostergaard P et al. Milroy disease. In: Pagon RA, Adam MP, Ardinger HH et al. (eds) GeneReviews. Seattle, WA: University of Washington, 1993.

14 Gordon K, Schulte D, Brice G et al. Mutation in vascular endothelial growth factor-C, a ligand for vascular endothelial growth factor receptor-3, is associated with autosomal dominant milroy-like primary lymphoedema. Circ Res 2013;112:956-60.

15 Ostergaard P, Simpson MA, Mendola A et al. Mutations in KIF11 cause autosomal-dominant microcephaly variably associated with congenital lymphoedema and chorioretinopathy. Am J Hum Genet 2012;90:356-62.

16 Jones GE, Ostergaard P, Moore AT et al. Microcephaly with or without chorioretinopathy, lymphoedema, or mental retardation (MCLMR): review of phenotype associated with KIF11 mutations. Eur J Hum Genet 2014;22:881-7.
17 Brice G, Mansour S, Bell R et al. Analysis of the phenotypic abnormalities in lymphoedema-distichiasis syndrome in 74 patients with FOXC2 mutations or linkage to 16q24. J Med Genet 2001;39:478-83.

18 Fang J, Dagenais SL, Erickson RP et al. Mutations in FOXC2 (MFH-1), a forkhead family transcription factor, are responsible for the hereditary lymphoedema-distichiasis syndrome. Am J Hum Genet 2000;67:1382-8.

19 Ostergaard P, Simpson MA, Connell FC et al. Mutations in GATA2 cause primary lymphoedema associated with a predisposition to acute myeloid leukemia (Emberger syndrome). Nat Genet 2011;43:929-31.

20 Ferrell RE, Baty CJ, Kimak MA et al. GJC2 missense mutations cause human lymphoedema. Am J Hum Genet 2010;86:943-8.

21 Ostergaard P, Simpson MA, Brice G et al. Rapid identification of mutations in GJC2 in primary lymphoedema using whole exome sequencing combined with linkage analysis with delineation of the phenotype. J Med Genet 2011;48:251-5.

22 Keppler-Noreuil KM, Rios JJ, Parker VE et al. PIK3CA-related overgrowth spectrum (PROS): diagnostic and testing eligibility criteria, differential diagnosis, and evaluation. Am J Med Genet A 2015;167A:287-95.

23 Keppler-Noreuil KM, Parker VE, Darling TN, Martinez-Agosto JA. Somatic overgrowth disorders of the PI3K/AKT/mTOR pathway \& therapeutic strategies. Am J Med Genet C Semin Med Genet 2016;172:402-21.

Address for correspondence: Professor Sahar Mansour, South West Thames Regional Genetics Service, St Georges University of London, London SW17 ORE, UK.

Email:smansour@sgul.ac.uk
Assessing trainees in the workplace An e-learning module for secondary care doctors

Three hours of CPD-approved interactive learning covering:

$>$ feedback

> supervised learning events (SLEs)

$>$ workplace-based assessments (WPBAs)

$>$ the role of the Annual Review of Competence Progression (ARCP).

For more information please visit: www.rcplondon.ac.uk/elearning
Royal College of Physicians

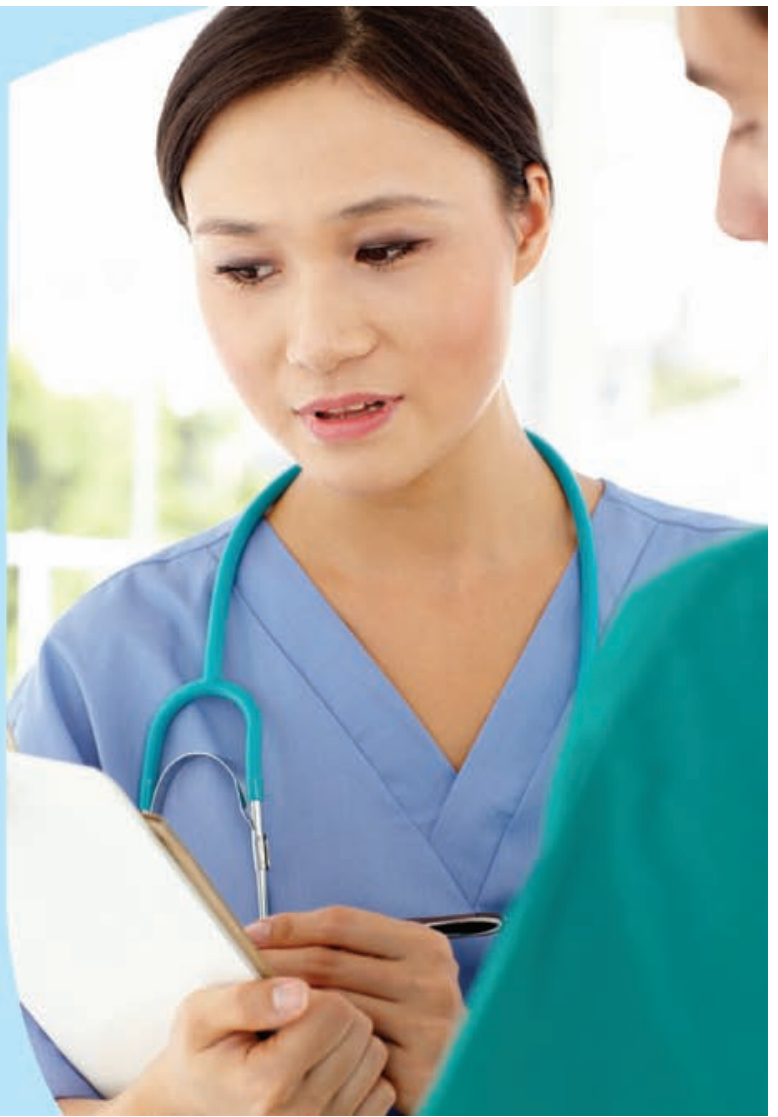

